\title{
Kimyasal, Biyolojik, Radyasyon ve Nükleer (KBRN) Olaylarda Psikososyal Bakım
}

\author{
Nuray DEMİRALP1 ${ }^{1}$, Kemal DEMİRALP² ${ }^{2}$ Ayşe ÜTÜK³ ${ }^{\text {, Ömer Faruk ÜTÜK }}{ }^{4}$
}

\begin{abstract}
Özet
Afetler ani, çoğunlukla nerede ve ne zaman olacağı tahmin edilemeyen, çok sayıda insanın etkilendiği, ekonomik, çevresel kayıpları, yıkıcı etkileriyle toplumun bununla başa çıkamaması ile karakterize bir durumdur. Bireyleri (örneğin çocuklar, ebeveynler, ilk müdahale edenler), acil yardım, sivil toplum kuruluşları (örneğin tıbbi acil durum ekipleri, halk sağlı̆̆ kuruluşları, itfaiye ekipleri) ve toplumu etkilemektedir. Afetler verdikleri zararlar nedeniyle bireyler ve toplumların yaşamlarında derin izler bırakan olaylardır. Yaşanan afet ve acil durumun bireyler ve toplumlar üzerindeki yıkıcı etkilerini en aza indirmek için en fazla ihtiyaç duyulan hizmet alanı psikososyal destektir. Psikososyal destek; hayatın normale dönüştürülmesi için gösterilen çabaların psikolojik ve sosyal açıdan değerlendirilmesine olanak sağlayan, bütüncül bir bakış açısını ve çok disiplinli bir müdahaleyi gerektiren hizmetlerdir. Kimyasal, biyolojik, radyolojik veya nükleer (KBRN) olaylar söz konusu olduğunda felaketler veya krizler bağlamında aynı şekilde psikososyal bakım müdahalelerine ihtiyaç vardır. Bununla birlikte, KBRN olayları acil durum planlaması ve afet hazırlığında ayrı bir tema oluşturduğundan psikososyal bakım üzerindeki etkilerini sistematik olarak araștırmak önemlidir.
\end{abstract}

Bu çalışmada KBRN olaylarında psikososyal bakımda genel kurallar üzerine durulmuş ve KBRN olaylarında afet ve acil durum olaylarından farklı psikososyal durumlar açıklanmaya çalışılmıştır.

İncelenen literatür çalışmalarında; KBRN ile ilgili psikososyal bakım ile ilgili hususlar konusunda çoğu çalışmada genel olarak varılan sonuç; genel afet sonrası psikososyal bakım kılavuzlarına benzer veya tamamlayıcı niteliktedir. Dikkate değer farklar ise iletişim, KBRN ajanlarına maruz kalma, kirlenme (kontaminasyon) ve KBRN olaylarına yönelik özel hazırlı gereksinimlerine vurgu yapılmaktadır. Ülkemizde ise KBRN olayların psikososyal etkileri ve psikososyal bakım ile ilgili çalışmalara çok az rastlanmaktadır. Bu alanla ilgili özellikle saha çalışmaları yapılarak literatüre büyük katkı sağlayacağı düşünülmektedir.

Anahtar Kelimeler: KBRN, Psikososyal Bakım, Eğitim

\footnotetext{
1 Öğr. Gör., Kastamonu Üniversitesi, Bozkurt MYO, Sivil Savunma ve İtfaiyecilik Programı, Kastamonu İlgili yazar/Corresponding author e-posta: ndemiralp@kastamonu.edu.tr ORCID No: 0000-0002-3002-7752

2Bağımsız Araștırmacı / Independent Researcher

e-posta: emaldemiralp@hotmail.com ORCID No: 0000-0002-9420-317X

3Öğr. Gör., Kastamonu Üniversitesi, Bozkurt MYO, Sivil Savunma ve İtfaiyecilik Programı, Kastamonu e-posta: aongun@kastamonu.edu.tr ORCID No: 0000-0001-6527-8917

${ }^{4}$ Kastamonu Üniversitesi, Abana Sabahat-Mesut Yılmaz MYO, Doğalgaz ve Tesisatı Teknolojisi Programı, Kastamonu e-posta: ofutuk@kastamonu.edu.tr ORCID No: 0000000346586652
} 


\title{
Psychosocial Care in Chemical, Biological, Radiation and Nuclear (CBRN) Events
}

\begin{abstract}
Disasters are characterized by the inability of the society to cope with sudden, unpredictable onset, large numbers of people affected by economic, environmental losses and destructive effects. It affects individuals (e.g. children, parents, first responders), emergency aid, nongovernmental organizations (e.g. medical emergency teams, public health organizations, fire brigades) and society. Disasters are associated with a significant psychological burden for affected people. Psychosocial care aims to address mental health problems and needs. It includes all support and care for the psychological well-being and health of affected people during and after a disaster for individuals as well as for communities. Psychosocial care interventions are needed in the context of disasters or crises in the case of chemical, biological, radiological or nuclear (CBRN) events. However, it is important to systematically investigate the impact on psychosocial care as CBRN events are a separate theme in emergency planning and disaster preparedness.
\end{abstract}

In this study, general rules of psychosocial care in CBRN events are discussed and different psychosocial conditions in CBRN events are to be explained.

General conclusion after examining literature studies related to psychosocial care in CBRN is that literature examined is either similar or complementary to the guidelines on psychosocial care. However, there are some significant differences on communication, exposure to CBRN agents, contamination and special preparation requirements for CBRN events. In our country, there are very few studies on psychosocial effects and psychosocial care of CBRN events. It is suggested that field studies could do a great contribution to the literature.

Keywords: CBRN, Psychosocial Care, Education

\section{GíRİ̧}

Son yıllarda hızla gelişen teknoloji ve artan terör olayları gibi kimyasal, biyolojik, radyolojik ve nükleer (KBRN) maddeleri içeren olayların olasılığı da artmıştır. Bu gibi olaylar hala nispeten düşük bir olasılık olsa da, kanıtlar bu tür bir olayın gerçekleşmesi durumunda toplum üzerinde büyük bir etkiye sahip olacağını göstermektedir (Alexander ve Klein, 2006; O’Brien, 2011; Schneidmiller, 2012). KBRN ajanlarının kolay fark edilememesi, maruziyete bağlı sonuçlarının genellikle bilinmemesi ve kontaminasyondan kaynaklanan gecikmiş etkiler, insanlar arasında korku, panik ve anksiyeteye neden olabilmektedir (Sheppard vd.,2006; Perry ve Lindell, 2003; Cornish, 2007).

Afet sonrası ortaya çlkabilecek psikolojik uyumsuzlukların/ bozuklukların önlenmesi, aile ve toplum düzeyinde ilişkilerin kurulması ve geliştirilmesi, etkilenenlerin 'normal' ya da yeni yaşamlarına geri dönmesi sürecinde birey, aile ve toplumun kendi kapasitelerini fark etmeleri ve güçlenmeleri ayrıca ileride ortaya çıkabilecek afetlerle başa çıkmaları amacıyla afet döngüsünün her aşamasında düzenlenen çok disiplinli hizmetler bütününe afetlerde psikososyal hizmetler denir (Reyes ve Elhai, 2004; Seynaeve, 2001).

Psikososyal bakım; bireylerin yanı sıra topluluklara yönelik bir olay sırasında ve sonrasında etkilenen insanların psikolojik iyiliklerine ve sağlığına yönelik tüm destek ve bakımı kapsar. KBRN olayları söz konusu olduğunda felaketler veya krizler bağlamında psikososyal bakım 
müdahalelerine ihtiyaç vardır (Neria vd.,2009; Norris vd., 2002). Bu tür olaylar, toksik (zehirli) ve tehlikeli kimyasallar / materyaller, kimyasal ve biyolojik savaş ajanları veya radyolojik materyaller gibi KBRN ajanlarının dâhil edilmesi ile karakterizedir. İnsanlar KBRN olayları ve maddelerine endüstriyel kazalar yoluyla; örneğin, 2011 Fukushima Daiichi nükleer felaketi, 1986 Çernobil felaketi, 1989 Exxon Valdez Petrol sızıntısı, savaşlar nedeniyle; örneğin 1991 Körfez Savaşı, Hiroşima ve Nagazaki'nin 1945 atom bombası, 1. Dünya Savașı sırasında hardal gazı ve göz yaşartıcı gaz kullanımı veya terörizm olayları; örneğin, 2001 ABD Şarbon saldırıları, 1995 Tokyo sarin saldırıları nedeniyle maruz kalabilmektedirler (Lemyre vd., 2010). Pekçok çalışma KBRN ajanlarının psikososyal etkileri fiziksel etkilerden daha büyük olduğunu göstermektedir (Kavana vd., 2001). Yapılan son çalışmalar 1986'da Çernobil'de meydana gelen nükleer kazanın derin psikososyal etkileri olan en büyük halk sağlığı sorunu olduğunu göstermektedir (Bromet, 2012). İstatistikler 2004 yılında 144 milyon insanı etkileyen 2780 teknolojik felaket yaşandığını göstermektedir (Gouweloos vd., 2014). Geçmişte yaşanan bu gibi olaylar günümüzde de maalesef görülmektedir. Bu nedenle KBRN olaylarına yönelik, birey ve toplumları içine alan, psikososyal bakım sağlama konusunda güçlü ve ortak bir yaklaşım aranmaktadır (Bonanno vd., 2010; Gouweloos vd., 2014).

\section{AFET SONRASI PSIKOSOSYAL BAKIM: GENEL KURALLAR VE REHBERLİK}

Çeşitli kurumlar ve otoriteler teknolojik nedenler, çeşitli kazalar ya da kötü niyetli eylemlerde olduğu gibi, her türlü doğal felakete hazırlanmada ve oluşabilecek etkilere cevap vermede yardımcı olmak amacıyla afetlerden sonra psikososyal bakımda genel standartlar geliștirmek için çeşitli girişimlerde bulunmuşlardır. Hobfoll ve ark.(2007) yaptıkları araștırmalar sonucunda, afet ve KBRN olaylarından etkilenen kişilere müdahalede bulunan meslekler için yardımcı olabilecek beş "temel ilkeyi” formüle etmişlerdir. Bunlar güvenlik, sakinleşme, bireysel ve topluluk etkinliği, bağlllık ve umut duygusu geliştirmektir (Dückers, 2013 , Hobfoll vd, 2007). Afetler sonrası psikososyal yardım hizmetlerini kolaylaştırmaya yönelik olarak tüm Avrupa ülkelerinde kullanılmak üzere Avrupa Travmatik Stres Ağı (The European Network for Traumatic Stress) rehberi hazırlanmıştır. Bu rehber, afete maruz kalmış olanlara psikososyal destek sağlamayı ve travma sonrası stres alanında elde edilen uzmanlık deneyiminin Avrupa çapında paylaşımını hedeflemektedir. Avrupa Travmatik Stres Ağı (TENTS)'na göre psikososyal hizmet, duygusal destek ve pratik yardımı içermektedir. Kaygllı kişileri kısa süre içinde rahatlatmak ve pratik yardım sağlamak, travma mağdurlarına uzun süreli psikolojik destek vermek veya travma uzmanlarının verdikleri hizmetler de psikososyal hizmetler kapsamındadır. Bireyler bu durumlarda öncelikle ailelerinden, arkadaşlarından ve içinde bulundukları topluluktan destek alırlar. Verilmesi düşünülen tüm hizmetlerin bu destek sistemini bütünleyici olması gerekir. Bu nedenle, psikososyal hizmetler yürütülürken bireylerin, başta aileleri ve içinde bulundukları topluluklar olmak üzere sosyal çevreleri dikkate alınması önerilmektedir (Bisson vd, 2010).

Afete maruz kalanların büyük bölümü genellikle kurtarma sırasında ve olaydan hemen sonraki erken dönemde yardıma ihtiyaç duymaktadır. Bununla birlikte, olaydan sonraki ilk üç yıl, hatta daha uzun süreyle bölgede destek ekiplerinin bulunması veya ihtiyaç duyan kişileri gerekli yerlere yönlendirebilecek hizmetlerin sağlanması gerekebilmektedir. TENTS ilkelerine göre topluma yönelik psikososyal hizmet etkinliklerine örnekler şu şekilde sıralanmaktadır: (Hobfoll vd, 2007).

- Halkın gazete, televizyon, radyo ve internet gibi iletişim kanalları aracılığıyla psikososyal yardımdan haberdar edilmelidir.

- Afet mağdurlarına duygusal destek sağlayan bir telefon yardım hattı ve psikososyal hizmetler içeren bir web sitesinin hazırlanmalıdır.

- İnsanların afet hakkındaki düşüncelerini, yorumlarını dinlemek, parçaları bir araya getirerek bu deneyimi yeniden anlamlandırmaya çalışılmalıdır. 
- Travmaya verilen tepkiler ve bununla nasıl başa çıkılacağı konusunda, travmaya maruz kalmış kişilerin çoğunun yaşadığı ortak duyguları da içeren broşürler hazırlanarak, travma mağdurlarını eğitmek, bu sayede kişilerin kendi yaralarını sarabilmelerini sağlamak ve yardıma gereksinimi olanlar için iletişim numaraları verilmelidir.

- Olaydan kaynaklanan problemlerle nasıl başa çıkılacağı hakkında bilgi verilmelidir (ör; yas, yoğun duygular, ailevi sıkıntılar, uyku bozukluğu ve işte yaşanan zorluklar).

- Bölgede sağlık, sosyal ve eğitim alanında çalışanları yaşanan travmanın uzun süreli psikopatolojik sonuçları ve toplumsal hizmet modeli konusunda bilgilendirilmelidir.

- Psikososyal sorunlar yaşayanları saptamak ve daha ileri bir müdahaleye gereksinim duyup duymadıklarını değerlendirilmelidir.

- Gerektiğinde, psikolojik ve farmakolojik değerlendirme ve tedavi için uzmanlardan destek alınmalıdır.

- Özel bazı gereksinimleri olanların uzman kişiler tarafından ya da uzman kişiler tarafından süpervize edilen klinisyen/danışmanlar tarafından tedavisi sağlanmalıdır.

- Afetten doğrudan etkilenenler ve onların aileleriyle proaktif iletişim kurulmalıdır. (ör; duygusal destek telefon yardım hattı veya travma danışmanı yoluyla)

- Sürekli ve uzun süreli psikososyal hizmet sağlayabilmek amacıyla bölgesel kaynakların geliştirilmeli ve güçlendirilmelidir.

\section{KBRN OLAYLARINDA PSİKOSOSYAL BAKIM}

Afetlere maruz kalmak sadece etkilenenler için değil aynı zamanda toplum içinde oldukça ağır yükler getirmektedir (ISTSS, 2003). Bu çerçevede programlanan afetlerde psikososyal hizmetlerin iki temel bakış açısı vardır; birincisi afetten etkilenen toplumu yeniden inşa etmek ve toplum kaynaklarını tekrar işler hale getirmek, ikincisi etkilenen bireylere müdahale etmek ve psikolojik bozuklukların ortaya çıkışını önlemektir ( Reyes ve Elhai, 2004).

\subsection{Risk ve Kriz İletişimi}

Yetkili makamlardan ve uzmanlar gelen net olmayan veya halk tarafından tam anlaşılmayan mesajlar, halk arasında belirsizliği ve endișeyi arttırdığı ve insanlarda psikososyal sorunlara ek olarak tıbbi tedaviye uymama veya tahliye tavsiyelerini görmezden gelme gibi riskli davranışları artırabilmektedir (Lemyre vd, 2010b, Rubin vd, 2012, Wessely, 2005). KBRN olayları yaşandığında açık, net ve kesin bir bilginin verilmemesi, KBRN olaylarında karmaşıklığa ve insanların paniklemesine yol açarak tıbbi tedaviyi de güçleştirmektedir. KBRN olaylarında insanları bilgilendirmeyle ilgili öneriler aşağıda sunulmuştur (Hick vd., 2011):

- Tek merkezi bilgi servisi kurulmalıdır.

- Topluluk üyeleri ve liderlerle yakın çalışılmalıdır.

- Medya ile işbirliğine dayalı bir ilişki geliştirilmeli ve belirsizliği artırabilecek söylentileri veya yanlış bilgileri önlemek için medyaya kaliteli bilgi sağlanmalıdır.

- KBRN ajanları, temel sağlık etkileri ve diğer bilimsel konular hakkında devlet liderleri ile birlikte güvenilir medya aracıllğ̆ ile toplum bilgilendirilmelidir.

- Popüler haber medyalarını kullanılmalıdır. 


\section{2. Ĕ̈itim, Öğretim ve Uygulama}

En çok kullanılan psikososyal müdahale araçlarındandır. Gerek afetten etkilenenlere gerekse psikososyal destek uygulamalarında çalışan ve çalışma olasılığı bulunan kişilere (psikologlar, sosyal hizmet uzmanları, kamp yöneticileri, öğretmenler, sivil toplum kuruluşu çalışanları, toplum liderleri, gönüllüler gibi) eğitim yoluyla ulaşmak önemlidir. Bu nedenle afet ve acil durumdan sonra vatandaşa yönelik psikososyal eğitimlerin, hazırlık döneminde ise personele yönelik beceri geliştirme eğitimlerinin verilmesi gerekmektedir. Afetlere hazırlık konusunda eğitim; endişeyi, kayıp beklentisini, hazırlıklı olma tutumunu ve risk algısını etkilemektedir. Toplumun her kesimine ulaşmak (örn; kadınlar), aşağıdan yukarıya yaklaşım (yani yerel toplumsivil toplum örgütleri), toplumda başa çıkma tutum ve davranışlarının, kontrol ve öz-yeterlilik duygularının güçlendirilmesi, yasal revizyonlar, güven ve politik kararlılık, sorumluluk ve sahiplenmeyi arttırmak, örgütlenme (bireyden-yerel toplum-merkezi idare), süreklilik, kurumsallaşma konularına önem vermek gerekmektedir (Karancı, 2012).

Afetlerden etkilenen topluluğa yönelik, psikososyal eğitim müdahalesi, akut ve kronik stres tepkilerini anlatan broşür dağıtımı, halka açık forumların düzenlenerek gerek toplum liderleri gerek ruh sağlığı uzmanlarının katılımıyla tartışmaların düzenlenmesi, radyo-televizyon ve diğer medya organlarınca afetler sonrasında ortaya çıkan sıkıntılara yönelik bilgi yayılması gibi yöntemler kullanılarak yapılabilir. Bu yöntemlerde amaç; ruh sağlı̆̆ koruyucu kapasitesinin harekete geçirilmesi ve ortaya çıkabilecek afet durumlarında halkın olumsuz durumlara karşı olumlu başa çıkma yollarını kullanmalarını sağlamaktır (Reyes and Elhai, 2004).

Pek çok çalışma, afet ya da benzeri bir durumda sağlık sisteminin hazır oluşluğu ve etkilenen topluluğa özellikle de yüksek risk gruplarına yardımda bulunanların eğitimi üzerine odaklanmaktadır. Afet ya da benzeri bir durumda, sağlık sisteminin önemli bir rolü vardır; etkilenen bir toplum hem acil müdahaleye hem de uzun vadeli sağllk hizmetlerine ihtiyaç duyar. Sağlık sistemi KBRN olayından kısa bir süre sonra, KBRN ile ilişkili problemlerden fiziksel olarak direkt maruz kalanlar ile maruz kalma korkusu nedeni ile hastaneye başvuran çok sayıda insanla karşı karşıya kalabilir. Örneğin, 2005 yılında Tokyo sarin saldırılarının ardından ve 1987'de Brezilya'nın Goiania kentindeki radyolojik kirlenme olayından sonra bu gibi durumlarla karşılaşılmıştır ( Knudson, 2001). Sağlık sistemindeki aksaklıkları önlemek ve mağdurlara en uygun kısa uzun süreli psikososyal bakımı sağlamak amacıyla bu alanda calışan sağlık profesyonelleri icin aşağıda önerilerde bulunulmuştur (Becker, 2005 , Benedek vd, 2002 , Fullerton vd, 2004 , Hall vd, 2002 , Markel vd, 2008 , Noy, 2004 ).

- Kirlenme semptomlarını hızlı bir șekilde teşhis edebilmek ve tedavi sağlayabilmek için sistemin hızlı bir şekilde harekete geçirilmesi planlanmalıdır.

- Farklı kuruluşlar (tıbbi sistem, acil müdahale ekipleri, halk sağlığı kuruluşları, yetkililer, vb.) arasında hızlı bilgi dağıtımı için bir (elektronik) ağ geliştirmeli ve koordine edilmelidir.

- Arındırma ve karantina önlemleri için hazırlanılmalıdır.

- Tıbbi problemleri olanları, maruz kalma korkusundan dolayı semptomları olanlardan ayırt etmeye yardımcı olan bir triyaj sistemi uygulanmalı ve bu konuda başarılı olabilmek icin, ruh sağlığı hizmetleri ile halk sağlığı hizmetleri acil müdahale hizmetleriyle birleștirilmelidir.

- Korku, öfke ve somatik semptomlar gibi afetlerden sonra psikolojik sorunları saptayabilme ve cevap verme konusunda eğitim alınmalıdır.

- Geç radyasyona bağlı hasar veya kanser ya da psikiyatrik bozukluklar gibi ruhsal yaralanmaları tespit etmek için uzun vadede ihtiyaç duyulan takip ve kayıtlar hazırlanmalıdır. 
Acil müdahale ekipleri (itfaiye, arama kurtarma ekipleri, polis vb.) ve sağlık personeli de KBRN ajanlarının (sağlık) etkileriyle ilgili eğitim almalı ayrıca kişisel koruyucu ekipmanlarla uygulamalı senaryolar üzerinden eğitilmelidir. KBRN olayı gerçekleştiğinde uygun müdahalede bulunabilmek için kişisel koruyucu donanımlar kullanılmalıdır. KBRN olaylarının psikolojik etkileriyle başa çıkma becerilerini geliştirmelidir. Acil müdahale ekiplerinin, KBRN olayı yaşandığı anda; KBRN ile ilgili kontaminasyon prosedürlerini bilmesi ve bu süreçte, aileleriyle iletişim kurmaları müdahale konusundaki kaygılarını azaltmada önemli olabilmektedir (O'Boyle vd., 2006).

\subsection{Psikolojik İlk Yardım ve Danışmanlık}

Kuruluşlar arası daimi komite (IASC)'ye göre, psikolojik ilk yardım; acı çeken ya da desteğe ve yardıma ihtiyaç duyulan kişiye sunulan insani ve destekleyici müdahale olarak tanımlanmaktadır. Psikolojik ilk yardım, afetten etkilenenlerin duygularını ve yaşadıklarını ifade etmelerine olanak verilmesi ve temel psikolojik bilgilerin iletilmesi aracılığıyla rahatlamalarına, yaşadıkları ve hissettiklerini anlamlandırmalarına yardımcı olmayı hedefler (IASC, 2003). Dünya Sağlık Örgütü'ne göre, psikolojik ilk yardım aşağıdaki konuları içermektedir:

- Kişileri zorlamayan pratik bakım ve destek sağlanmalıdır,

- İhtiyaç ve kaygıları belirlenmelidir,

- İnsanların temel ihtiyaçlarını karşılamalarına yardımcı olunmalıdır (su, gıda, bilgi alma, barinma vb.),

- İnsanları konuşmaya zorlamadan dinlenmelidir,

- Susturmaya çalışmadan rahatlatıp sakinleşmelerine yardımcı olunmalıdır.

- İnsanların bilgi edinmesi, hizmetlere ve sosyal desteklere ulaşmaları için yardım sağlanmalıdır.

- Kişileri gelecekteki olası zararlardan korunmalıdır (WHO, 2011).

\section{TARTIŞMA VE SONUÇ}

Afet veya acil durumlarda KBRN ajanlarının (risk) fiziksel, zihinsel, davranışsal ve sosyal sağlık üzerinde spesifik etkilere sahip olduğunu incelenen çalışmalar bulunmaktadır. KBRN olaylarında psikososyal bakımın diğer olay türlerinden ne ölçüde farklı olduğu konusundaki çalıșmalardaki öneriler doğrultusunda; psikososyal müdahalelerin çoğunun afet sonrası psikososyal bakım ile ilgili genel kllavuz ilkelere uygun veya tamamlayıcı olduğu sonucuna varabilmektedir. Genel olarak TENTS'in önerileri KBRN olaylarına uygulanabilmektedir. Afet ve KBRN olaylarında etkilenen insanlara, pratik ve sosyal destek sağlanmalı özellikle yüksek riskli gruplara (çocuklar, yaşlılar, önceki zihinsel bozuklukları olan insanlar ve etnik azınlıklar) zamanında tedavi sağlanmalıdır.

Afetler ve KBRN olaylarında; alınacak önlemler, psikososyal bakım özellikleri, risk faktörleri ve psikososyal problemler bakımından sürec benzerdir. Psikososyal bakım sunarken dikkate alınması gereken risk faktörlerinin birçoğu, bir KBRN olayında farklı değildir; örneğin, travmatik maruziyetin şiddeti, önceki ruh sağlığı sorunları, sevdiklerin ölümü, kendine ya da aile üyelerinin yaralanması, kadın cinsiyeti, düşük sosyo-ekonomik durum, sigara içme, etnik köken ve tahliye gibi. ( Bonanno vd, 2010, Neria vd, 2009). Çalışmaların çoğunda belirtildiği gibi, KBRN olaylarında psikososyal acıdan, özellikle literatürde iki tema ele alınmıştır, bunlar; kriz risk iletişimi ve sağlık bakım sisteminin özel hazırlık ihtiyaçlarıdır.

KBRN olaylarında psikososyal bakımda, kriz döneminde iletişim, kirlenme ve arındırma (dekontaminasyon) etkileri konusundaki belirsizliği azaltmak oldukça önemlidir. KBRN 
olaylarını karmaşık hale getiren diğer bir hususta, meslekten olmayan kişilerin ve uzmanların, radyasyon veya toksik materyaller gibi herhangi bir toksik kaynaktan sağlık riskleri konusunda genellikle aynı fikirde olmadıklarıdır. Uzmanlar, fikirlerini istatistiklere dayandırırken, meslekten olmayan kişiler ise, kişisel deneyim, paylaşılan öyküler veya sansasyonel medya kaynakları ve tüm toksik maddeleri tek bir grup olarak düşünme eğilimi gibi ifadeler bu süreci oldukça zorlaştırmaktadır ( Cwikel vd., 2002).

KBRN olayı ile karşı karşıya kalındığında, acil müdahale ekiplerinin ve sağlık hizmetleri personellerinin özel hazırlık ihtiyaçları yapmaları gereklidir. Özellikle zor bir görev olan KBRN ajanlarına maruz kalmanın fiziksel sonuçları ile bu olayla karşılaşanların verdiği psikolojik tepkiler arasında ayrım yapmaktır. Ayrıca, insanları tedavi ederken, acil yardım ekiplerininde kontamine olmamaları için kişisel koruyucu ekipmanların kullanım prosedürlerine uymaları gerekmektedir. Özellikle sağlık riskleri konusunda belirsizliği yüksek olan durumlarda, eğitim ve hazırlık çalışmaları acil yardım ekipleri arasındaki psikososyal sorunları en aza indirgemeye, azaltmaya ve kontrol duygularını teşvik etmeye yönlendirilmelidir (Considine ve Mitchell, 2009). KBRN olaylarının psikososyal sonuçlarıyla ilgili olarak, Wessely (2005)“Akut etkiler korktuğumuzdan daha az, uzun vadeli etkiler ise tahmin ettiğimizden daha sinsi ve yönetilmesi zor" şeklinde" ifade etmiştir (Wessely, 2005, s-6). Bu çalışma, öncelikle bir KBRN felaketinden veya olayından sonra ortaya çıkabilecek zihinsel, davranışsal veya sosyal sorunların doğasına veya yaygınlığına değil, psikososyal bakım üzerine odaklanmıştır. Bir KBRN olayından sonra psikososyal müdahalelerle ilgili uluslararası bilgi birikimini bir araya getirmek, araştırmadaki boşlukları tespit etmek ve en uygun psikososyal bakım için önerileri tanımlamaktır.

Sonuç olarak, ülkemizde daha çok afet ve acil durumlarda psikososyal bakım üzerine durulmuş olup KBRN olaylarında psikososyal bakım ile ilgili bir literatür bulunmamaktadır. Ayrıca KBRN alanında görev yapan tüm acil müdahale ekiplerinin; itfaiye, polis, arama-kurtarma birlikleri gibi alanda çalışan ve tıbbi müdahalede bulunan personellerin KBRN ile ilgili zorunlu eğitim almaları ve senaryolar üzerinden tatbikatların yapılması, halka KBRN olaylarının etkileri, alınacak önlemler vb. konularda afiş,broşür ve kamu spotları ile eğitimler sağlanmalıdır.

\section{KAYNAKLAR}

Alexander, D. A., \& Klein, S. (2006). The challenge of preparation for a chemical, biological, radiological, or nuclear terrorist attack. The Journal of Postgraduate Medicine, 52(2), 126-131.

Becker, S. M. (2005). Addressing the psychosocial and communication challenges posed by radiological/nuclear terrorism: key developments since NCRP Report No. 138. Health Physics, 89(5), 521530 .

Benedek, D. M., Holloway, H. C., \& Becker, S. M. (2002). Emergency mental health management in bioterrorism events. Emergency Medicine Clinics, 20(2), 393-407.

Bisson, J. I., Tavakoly, B., Witteveen, A. B., Ajdukovic, D., Jehel, L., Johansen, V. J., ... \& Sezgin, A. U. (2010). TENTS guidelines: development of post-disaster psychosocial care guidelines through a Delphi process. The British Journal of Psychiatry, 196(1), 69-74.

Bonanno, G. A., Brewin, C. R., Kaniasty, K., \& Greca, A. M. L. (2010). Weighing the costs of disaster: Consequences, risks, and resilience in individuals, families, and communities. Psychological science in the public interest, 11(1), 1-49.

Bromet, E. J. (2012). Mental health consequences of the Chernobyl disaster. Journal of radiological protection, 32(1), 71.

Considine, J., \& Mitchell, B. (2009). Chemical, biological and radiological incidents: preparedness and perceptions of emergency nurses. Disasters, 33(3), 482-497. 
Cornish, P. (2007). The CBRN system: assessing the threat of terrorist use of chemical, biological, radiological and nuclear weapons in the United Kingdom. Royal Institute of International Affairs,s-3.

Cwikel, J. G., Havenaar, J. M., \& Bromet, E. J. (2002). Understanding the psychological and societal response of individuals, groups, authorities, and media to toxic hazards. In Toxic Turmoil (pp. 39-65). Springer, Boston, MA.

Dückers, M. L. (2013). Five essential principles of post-disaster psychosocial care: Looking back and forward with Stevan Hobfoll. European journal of psychotraumatology, 4(1), 21914.

Fullerton, C. S., Ursano, R. J., \& Norwood, A. E. (2004). Planning for the psychological effects of bioterrorism. Bioterrorism: Psychological and public health interventions, 2-15.

Gouweloos, J., Dückers, M., Te Brake, H., Kleber, R., \& Drogendijk, A. (2014). Psychosocial care to affected citizens and communities in case of CBRN incidents: a systematic review. Environment international, 72, 46-65.

Hall, M. J., Norwood, A. E., Fullerton, C. S., \& Ursano, R. J. (2002). Preparing for bioterrorism at the state level: Report of an informal survey. American Journal of Orthopsychiatry, 72(4), 486-491.

Hick, J. L., Weinstock, D. M., Coleman, C. N., Hanfling, D., Cantrill, S., Redlener, I., ... \& Knebel, A. R. (2011). Health care system planning for and response to a nuclear detonation. Disaster medicine and public health preparedness, 5(S1), S73-S88.

Hobfoll, S. E., Watson, P., Bell, C. C., Bryant, R. A., Brymer, M. J., Friedman, M. J., ... \& Maguen, S. (2007). Five essential elements of immediate and mid-term mass trauma intervention: Empirical evidence. Psychiatry: Interpersonal and Biological Processes, 70(4), 283-315.

ISTSS, (2003). International Working Group on Traumatic Stress, International Society for Traumatic Stress Studies, Psychosocial Policy and Practice in Social and Humanitarian Crises: An overview.Erişim Tarihi:20.04.2020

Karancı, N. (2012). 'Afetlerde Psikososyal Gereksinim ve Kaynak Belirleme', Ed. Gözden, M.,Öztan, N. Aker, T. Psikososyal Uygulamalar Eğitimi APHB: Ankara Ofis Ostim,s-51

Kawana, N., Ishimatsu, S. I., \& Kanda, K. (2001). Psycho-physiological effects of the terrorist sarin attack on the Tokyo subway system. Military Medicine, 166(suppl_2), 23-26.

Lemyre, L., Corneil, W., Johnson, C., \& Boutette, P. (2010). Psychosocial considerations about children and radiological events. Radiation protection dosimetry, 142(1), 70-76.

Lemyre, L., Johnson, C., \& Corneil, W. (2010). Psychosocial considerations for mass decontamination. Radiation protection dosimetry, 142(1), 17-23.

Markel, G., Krivoy, A., Rotman, E., Schein, O., Shrot, S., Brosh-Nissimov, T., ... \& Eisenkraft, A. (2008). Medical management of toxicological mass casualty events. Sat, 1, 19.

Neria, Y., Galea, S., \& Norris, F. H. (Eds.). (2009). Mental health and disasters. Cambridge University Press. Neria, Y., Nandi, A., \& Galea, S. (2008). Post-traumatic stress disorder following disasters: a systematic review. Psychological medicine, 38(4), 467-480.

Norris, F. H., Friedman, M. J., \& Watson, P. J. (2002). 60,000 disaster victims speak: Part II. Summary and implications of the disaster mental health research. Psychiatry: Interpersonal and biological processes, 65(3), 240-260. 
Noy, S. (2004). Minimizing casualties in biological and chemical threats (war and terrorism): the importance of information to the public in a prevention program. Prehospital and disaster medicine, 19(1), 29-36.

O'Brien, L. B. (2011). The evolution of terrorism since 9/11. FBI Law Enforcement Bulletin, September 2011. Retrieved on 3rd October 2012, from http://www.fbi.gov/stats-services/publications/lawenforcement-bulletin/september-2011/the-evolution-of-terrorism-since-9-11

O'Boyle, C., Robertson, C., \& Secor-Turner, M. (2006). Public health emergencies: nurses' recommendations for effective actions. Aaohn Journal, 54(8), 347-353.

Perry, R., \& Lindell, M. K. (2003). Understanding citizen response to disasters with implications for terrorism. Journal of Contingencies and Crisis Management, 11(2), 49-60.

Reyes, G., Elhai, J. D., (2004). Psychosocial interventions in the early phases of disasters. Psychotherapy: Theory, Research, Practice, Training. 441: 399-411.

Rubin, G. J., Chowdhury, A. K., \& Amlôt, R. (2012). How to communicate with the public about chemical, biological, radiological, or nuclear terrorism: a systematic review of the literature. Biosecurity and bioterrorism: biodefense strategy, practice, and science, 10(4), 383-395.

Sheppard, B., Rubin, G. J., Wardman, J. K., \& Wessely, S. (2006). Terrorism and dispelling the myth of a panic prone public. Journal of Public Health Policy, 27(3), 219 - 245.

Smith, E. C., Burkle, F. M., \& Archer, F. L. (2011). Fear, familiarity, and the perception of risk: a quantitative analysis of disaster-specific concerns of paramedics. Disaster medicine and public health preparedness, $5(1), 46-53$.

Seynaeve, G. J. R. (Ed.). (2001). Psycho-Social Support in Situations of Mass Emergency. A European Policy Paper Concerning Different Aspects of Psycho-Social Support for People Involved in Major Accidents and Disasters. Ministry of Public Health, Belgium.

Wessely, Simon. "Don't panic! Short and long term psychological reactions to the new terrorism: The role of information and the athorities." (2005): 1-6.

World Health Organization, (2011). Psychological First Aid: Guide for field workers, WHO Genewa. (Son Erişim Tarihi: 20.04.2020) 